2020

Marine Litter: Are There Solutions to This Environmental Challenge?

Thompson, Richard

http://hdl.handle.net/10026.1/17614

10.1007/978-3-030-45909-3_8

PROCEEDINGS OF THE 2ND INTERNATIONAL CONFERENCE ON MICROPLASTIC

POLLUTION IN THE MEDITERRANEAN SEA

Springer International Publishing

All content in PEARL is protected by copyright law. Author manuscripts are made available in accordance with publisher policies. Please cite only the published version using the details provided on the item record or document. In the absence of an open licence (e.g. Creative Commons), permissions for further reuse of content should be sought from the publisher or author. 


\title{
Disclaimer
}

'This is a copy of the accepted paper as submitted for publication. Readers are advised to refer to the final version of the paper which can be found at doi:10.1007/978-3-030-45909-3 8

\section{Marine litter: are there solutions to this environmental challenge?}

\section{Richard C. Thompson, Francesca De Falco}

\author{
Richard C. Thompson ( $\square)$ \\ School of Biological and Marine Sciences, University of Plymouth, Drake Circus, Plymouth, Devon \\ PL4 8AA, U.K. (R.C.Thompson@plymouth.ac.uk) \\ Francesca De Falco \\ Institute for Polymers, Composites and Biomaterials, National Research Council of Italy, Via Campi \\ Flegrei, 34, 80078, Pozzuoli, NA, Italy
}

\section{Introduction}

Between 1950 and 2015, it is estimated that 6300 Mt of plastic waste have been produced. Of this, around the $80 \%$ ended up in landfills or in the natural environment [1]. The combination of this type of waste disposal and of the durability and resistance to degradation of plastics, has led to the current ubiquitous and abundant presence of plastic debris in the environment. The greatest warning signal of this plastic pollution problems has come from marine environment, where it is estimated that $75 \%$ of all marine litter is plastic and this debris has been reported to be accumulating at the sea surface [2], on shorelines of the most remote islands [3], in the deep sea [4] and in arctic sea ice [5]. Despite first reports on marine plastic litter dates back to the 1960s (Kenyon \& Kridler, 1969) only recently it has been recognized as a pervasive global issue [1].

There is a range of evidence on the harm caused by marine litter; with negative impacts on commercial fisheries, maritime industries and infrastructures, as well as on a wide range of marine organisms as a consequence of entanglement and ingestion [6].

Plastic debris can be defined and described according to different characteristics including origin, polymer type, shape, size, colour or original use. However, the main classification used is about the size: macroplastic (>20 mm diameter), mesoplastic $(5-20 \mathrm{~mm})$ and microplastic $(<5 \mathrm{~mm})$ [7]. Since 
macroplastics are more visible, they have been for long time considered as one of the most concerning forms of plastic pollution. In fact, these items can be more easily recognized and categorised according to their original usage (i.e. fishing, packaging, or sewage related debris). More subtle and complicate is instead the pollution related to the presence of microplastics that, with accumulating data on the impact and consequences of such debris, has received increasing research interest and currently represents one of the greatest challenges in the fight against plastic pollution.

\section{Microplastics: definition and sources}

The presence of small plastic fragments in the open ocean was reported for the first time in the 1970s in the North Atlantic, during sampling campaigns with plankton tows [8]. However, it was not until 2004 that the term 'microplastics' was coined in a paper describing the long-term accumulation of plastic fragments with dimensions of few microns in beach, estuarine and subtidal sediments in the UK [9]. This terminology was subsequently considered during the International Research Workshop on the Occurrence, Effects, and Fate of Microplastic Marine Debris in 2009, where scientific experts agreed on using the name "microplastics" to define plastic particles smaller than $5 \mathrm{~mm}$. The workshop also distinguished microplastics according to their sources [10]. Microplastics are classified as "primary" if they are intentionally produced in such micro dimensions for direct usage or as precursors for other products, for example in cleaning products, cosmetics [11] and as air-blasting media. Instead, they are defined as "secondary" if they derive from the fragmentation of larger plastic debris, as a consequence of ultra-violet (UV) radiation and oxidation and/or physical forces from abrasion, wave-action and turbulence [12]. Secondary microplastic can also be generated as a consequence of items such as tyres and textiles becoming abraded during life in service $[13,14]$. The occurrence of these pollutants not only in marine environment, but also in freshwater systems [15]. Microplastics cannot be cost-effectively detected, collected for recycling or successfully removed, causing a range of negative economic and environmental concerns. Microplastics are able to interact with a very wide variety of marine organisms, from zooplankton to marine mammals [6]. Moreover, they may also present a toxic hazard to marine organisms, by accumulating persistent organic pollutants (POPs) already present in water, or by leaching additives added to plastics during their production or residual monomers or oligomers [16]. However, recent modelling work suggests that the importance of microplastics as a transport vector for sorbed contaminants is likely to be minimal in most scenarios [17].

To understand correctly the occurrence and impact of microplastic pollution, the EU [18] is directing efforts to compare and harmonise monitoring protocols, including those used for microplastics, with the scope of ensuring greater inter-comparability among data.

\section{Solutions and future challenges}

The success of plastics is mainly due to four key properties being light weight, durable, versatile and inexpensive. They have made plastics suitable for the most disparate applications, shaping modern society with numerous societal benefits in healthcare, agriculture, transport, construction and packaging [19].

However, the accumulation of plastic litter in the oceans is actually a symptom of a much wider problem - the accumulation of plastic waste. It is clear we have buried beneath the ground for future generations to deal with far more plastic than has accumulated in the oceans. The underlying issue is our linear use of plastics through short-lived applications to persistent waste. The combination of the growing human populations and the improvement of living standards, along with the increasing plastic production and a lack of consideration at the product design stage of a product fate after use, 
have led to the culture of a disposable convenience driven society with associated consumer behaviour unconcerned about the consequent environmental implications. By comparison with many other current environmental challenges, the benefits resulting from the use of plastics are not directly linked to the emission of plastic debris to the environment or to degradation of the environment. Hence, in theory at least, it is possible for society to retain the benefits of plastic products and at the same time reduce the quantity of plastic litter entering the environment [20].

In order to establish efficient prevention and mitigation strategies, the identification and comprehension of the different sources of marine plastic pollution is important to gain an accurate assessment of the quantities of plastics and microplastics entering the ocean, to provide an indication of regional or local 'hot spots' of occurrence, and to determine the feasibility of introducing management measures to reduce these inputs [21]. In general, the sources of marine plastic litter are quite well known, but what is still missing is consistent data on the relative importance of the different sources, mainly due to the lack of standardised protocols for replicable measurement of waste generation, collection rates, classification and waste disposal methods for rural areas and urban centers in countries around the world [1]. Therefore, potential solutions to mitigate this problem are widespread and complex and needs joint efforts from industry, governments, society and scientific research.

Starting from product design, disposal pathways for a product need to be considered right from the beginning. Although most plastics are inherently recyclable, many single-use items are not currently designed to be widely compatible with recycling. Long-term sustainable solutions require moving from a linear economy towards a more circular economy that takes into account the end-of-life of the product, leading to its recycling (when possible) or correct disposal [22]. In this respect, waste management frameworks should be improved: this is not just a problem for developing nations, even in industrialized nations with good waste management infrastructure there are generally very low levels of recycling and little evidence of product design being linked to the waste management options that are available. .

Governments also have a key role since they can create a legislative framework to stimulate mitigation actions of plastic waste at its sources. For instance, policies from governments in many nations to either ban the sale of single-use plastic bags, charge customers for their use and/or generate taxes from stores who sell them, resulting in a substantial reduction of their use [23]. Currently, there is no consistency of policies in this topic between countries, so a more effective and pragmatic global cooperation among the country governments is of striking importance. There is also a key need to government policies to help create a level and fair playing field for industry so that more reputable companies are not undermined by the less environmentally scrupulous.

Education, outreach and awareness raising are also important ways to address marine litter [24]. It has been suggested that marine litter can be used as a vehicle to inspire and promote more sustainable economies and lifestyles [25]. Improving and spreading public awareness of the problems caused by plastic pollution is the first step towards changing people's behaviour on plastic consumption.

Finally, advances in academic research from material science to waste treatment, are likely to be pivotal in optimising and evidencing new solutions or alternatives to our current approaches to design, use and dispose of plastics. For example, biodegradable or compostable polymers could perhaps replace traditional plastics for some applications, like single-use plastic items, and are sometimes promoted as way to reduce pollution also in marine environment. However, more studies are needed to assess the degradation rate of biodegradable or compostable polymers in a range of natural environments. In most cases, the potential advantages of these novel materials can only be reached in dedicated and specifically managed waste collection systems that provides conditions suitable for degradation. Yet there is often failure to communicate this to the consumer since labelling to facilitate appropriate disposal is lacking [26]. 
Microplastics represent a more specific issue that requires more complex and challenging actions. Preventing the emission of macroplastics in marine environments will certainly reduce the generation of microplastics by fragmentation. However, for other sources the best approach could be removal at source, for example by banning of microbeads in personal care products [23], or at the design and production stage by for example improving synthetic textile design so that garments release fewer fibres and last longer in service - such that they are on the whole more sustainable $[27,28,29]$.

\section{Conclusions}

Since the mass production of plastics commenced in the 1950s, global plastic production has increased almost exponentially. At the same time, plastic pollution and the generation of waste has increased accordingly, hence there is now an urgent need for prevention, mitigation and to a lesser extent remediation actions.

Key solutions to address plastic pollution are already available but there is a need for clear and independent evidence to guide the most appropriate choice of interventions as well as for coordinated action among the international community and several sectors/stakeholders. A synergistic approach should involve dedicated policies and regulations to prevent unnecessary plastic emissions in the environment, changes in product design and production to promote circular economy, and social science to better understand attitudes and perceptions about the issue and the solutions as well as to help raise awareness.

A key and largely missing element is support for academic research and collaboration across the disciplines, bringing together environmental and material scientists, waste managers, product designers, legal expertise as well as social scientist. Only by considering both the challenge and the solutions in a holistic manner, we can hope to reach optimal solutions and minimise the (currently high) risk of taking uniformed knee jerk reactions that may have far reaching negative consequences.

\section{References}

[1] Geyer, R.; Jambeck, J.; Law, K. L.: Production, use, and fate of all plastics ever made. Sci. Adv. 3, e1700782 (2017).

[2] Law, K.L.; Moret-Ferguson, S.; Maximenko, N.A.; Proskurowski, G.; Peacock, E.E.; Hafner, J.; Reddy, C.M.: Plastic Accumulation in the North Atlantic Subtropical Gyre.. Science 329, 1185-1188 (2010).

[3] Barnes, D.: Remote Islands Reveal Rapid Rise of Southern Hemisphere Sea Debris. Sci. World J. 5, 915-921 (2005).

[4] Woodall, L.C.; Sanchez-Vidal, A.; Canals, M.; Paterson, G.L.J.J.; Coppock, R.; Sleight, V.; Calafat, A.; Rogers, A.D.; Narayanaswamy, B.E.; Thompson, R.C.: The deep sea is a major sink for microplastic debris. R. Soc. Open Sci. 1, 140317-140317 (2014).

[5] Obbard, R. W.; Sadri, S.; Wong, Y.Q.; Khitun, A.A.; Baker, I.; Thompson, R. C.: Global warming releases microplastic legacy frozen in Arctic Sea ice. Earth's Future 2, 315-320 (2014).

[6] Gall, S.; Thompson, R.: The impact of debris on marine life.. Mar. Pollut. Bull. 92, 170-179 (2015).

[7] Thompson, R.C.; Moore, C.J.; vom Saal, F.S.; Swan, S.H.: Plastics, the environment and human health: current consensus and future trends. Philos. Trans. R. Soc. Lond. B. Biol. Sci. 364, $2153-$ 2166 (2009).

[8] Carpenter, E. J.; Anderson, S. J.; Harvey, G. R.; Miklas, H. P; Peck, B. B.: Polystyrene Spherules in Coastal Waters. Science 178, 749-750 (1972). 
[9] Thompson, R.C.; Olsen, Y.; Mitchell, R.P.; Davis, A.; Rowland, S.J.; John, A.W.G.; McGonigle, D.; Russell, A.E.: Lost at sea: where is all the plastic? Science 304, 838 (2004).

[10] Arthur, C.; Baker, J.; Bamford, H. In: Proceedings of the International Research Workshop on the Occurrence, Effects and Fate of Microplastic Marine Debris, 49. NOAA Technical Memorandum NOS-OR\&R-30 (2009).

[11] Napper, I.; Bakir, A.; Rowland, S.; Thompson, R.: Characterisation, quantity and sorptive properties of microplastics extracted from cosmetics. Mar. Pollu Bull. 99, 178-185 (2015).

[12] Barnes, D.; Galgani, F.; Thompson, R.C.; Barlaz, M.: Accumulation and fragmentation of plastic debris in global environments. Philos. Trans. R. Soc. B Biol. Sci. 364, 1985-1998 (2009).

[13] Napper, I.; Thompson, R.: Release of synthetic microplastic plastic fibres from domestic washing machines: effects of fabric type and washing conditions. Mar. Pollu Bull. 112, 39-45 (2016).

[14] De Falco, F.; Gullo, M. P.; Gentile, G.; Di Pace, E.; Cocca, M.; Gelabert, L.; Brouta-Agnésa, M.; Rovira, A.; Escudero, R.; Villalba, R.; Mossotti, R.; Montarsolo, A.; Gavignano, S.; Tonin, C.; Avella, M.: Evaluation of microplastic release caused by textile washing processes of synthetic fabrics. Environmental Pollution 236, 916-925 (2018).

[15] Eerkes-Medrano, D.; Thompson, R.C.; Aldridge, D.C.: Microplastics in freshwater systems: A review of the emerging threats, identification of knowledge gaps and prioritisation of research needs. Water Research 75, 63-82 (2015).

[16] Andrady, A.: The plastic in microplastics: A review. Mar. Pollut. Bull. 119, 12-22 (2017).

[17] Bakir, A.; O'Connor, I. A.; Rowland, S. J.; Hendriks, A. J., Thompson, R. C.: Relative importance of microplastics as a pathway for the transfer of hydrophobic organic chemicals to marine life. Environmental Pollution 219, 56-65 (2016).

[18] MSFD GES Technical Subgroup on Marine Litter: Marine Litter Technical Recommendations for the Implementation of MSFD Requirements. Joint Research Centre - Institute for Environment and Sustainability, Luxembourg (2011).

[19] PlasticsEurope: Plastics - the Facts 2017, Plastics Shape the Future. Brussels, Belgium https://www.plasticseurope.org/application/files/5715/1717/4180/Plastics_the_facts_2017_FINAL_ for_website_one_page.pdf (2018)

[20] Thompson, R.: Microplastics in the marine environment: Sources, consequences and solutions. In: Bergmann, M., Gutow L., Klages M. (eds.) Marine Anthropogenic Litter p. 185-200. Springer Open, New York (2015).

[21] GESAMP: Sources, fate and effects of microplastics in the marine environment: a global assessment. In: Kershaw, P.J. (ed.) IMO/FAO/UNESCO-IOC/ UNIDO/WMO/IAEA/UN/UNEP/UNDP Joint Group of Experts on the Scientific Aspects of Marine Environmental Protection. Rep Stud GESAMP No. 90, 96 p. (2015).

[22] Ellen MacArthur Foundation and McKinsey \& Company: The New Plastics Economy Rethinking the future of plastics. http://www.ellenmacarthurfoundation.org/publications (2016).

[23] Xanthos, D.; Walker, T. R.: International policies to reduce plastic marine pollution from singleuse plastics (plastic bags and microbeads): A review. Mar. Pollut. Bull. 118, 17-26 (2017).

[24] Hartley, B.L.; Pahl, S.; Holland, M.; Alampei, I.; Veiga, J.M.; Thompson, R.C.: Turning the tide on trash: Empowering European educators and school students to tackle marine litter. Marine Policy 96, 227-234 (2018).

[25] Veiga, J.M.; Vlachogianni, T.; Pahl, S.; Thompson, R.C.; Kopke, K.; Doyle, T.K.; Hartley, B.L.; Maes, T.; Orthodoxou, D.L.; Loizidou, X.I.; Alampei, I.: Enhancing public awareness and promoting co-responsibility for marine litter in Europe: The challenge of MARLISCO. Mar. Pollut. Bull. 102, 309-315 (2016). 
[26] Napper, I. E.; Thompson, R. C.: Environmental Deterioration of Biodegradable, Oxobiodegradable, Compostable, and Conventional Plastic Carrier Bags in the Sea, Soil, and Open-Air Over a 3-Year Period. Environ. Sci. Technol. 53, 4775-4783 (2019).

[27] De Falco, F.; Di Pace, E.; Cocca, M.; Avella, M.: The contribution of washing processes of synthetic clothes to microplastic pollution. Scientific Reports 9, 6633 (2019).

[28] De Falco, F.; Gentile, G., Avolio, R.; Errico, M. E.; Di Pace, E.; Ambrogi, V.; Avella, M.; Cocca, M. Pectin based finishing to mitigate the impact of microplastics released by polyamide fabrics. Carbohydrate Polymers 198, 175-180 (2018).

[29] De Falco, F.; Cocca, M.; Guarino, V.; Gentile, G.; Ambrogi, V.; Ambrosio, L.; Avella, M.: Novel finishing treatments of polyamide fabrics by electrofluidodynamic process to reduce microplastic release during washings. Polymer Degradation and Stability 165, 110-116 (2019). 